\title{
The associations of butyrate-producing bacteria of the gut microbiome with diet quality and muscle health
}

\author{
Jessica A Davis ${ }^{1, \star}$ (D), Fiona Collier ${ }^{2,3},{\text { Mohammadreza Mohebbi }{ }^{4} \text {, Julie A Pasco }}^{1,3,5,6}$, \\ Nitin Shivappa ${ }^{7,8}$, James R Hébert ${ }^{7,8}$, Felice N Jacka ${ }^{1,9,10,11}$ and Amy Loughman ${ }^{1}$ \\ ${ }^{1}$ IMPACT - The Institute for Mental and Physical Health and Clinical Translation, School of Medicine, Barwon Health, Deakin \\ University, Geelong, VIC, Australia \\ ${ }^{2}$ Geelong Centre for Emerging Infectious Diseases (GCEID), Barwon Health, Geelong, VIC, Australia \\ ${ }^{3}$ Barwon Health, Geelong, VIC, Australia \\ ${ }^{4}$ Biostatistics Unit, Faculty of Health, Deakin University, Geelong, VIC, Australia \\ ${ }^{5}$ Department of Medicine - Western Health, The University of Melbourne, St Albans, VIC, Australia \\ ${ }^{6}$ Department of Epidemiology and Preventive Medicine, Monash University, Prahran, VIC, Australia \\ ${ }^{7}$ Cancer Prevention and Control Program, University of South Carolina, Columbia, SC, USA \\ ${ }^{8}$ Department of Epidemiology and Biostatistics, Arnold School of Public Health, University of South Carolina, Columbia, \\ SC, USA \\ ${ }^{9}$ Centre for Adolescent Health, Murdoch Children's Research Institute, Parkville, VIC, Australia \\ ${ }^{10}$ Black Dog Institute, Randwick, NSW, Australia \\ ${ }^{11}$ James Cook University, Townsville, QLD, Australia \\ *Corresponding author. Email: j.davis@deakin.edu.au \\ F. N. Jacka and A. Loughman are joint senior authors.
}

(Received 28 April 2021; revised 21 June 2021; accepted 5 August 2021)

\begin{abstract}
This study aimed to investigate the relationships between diet quality, the relative abundance of butyrate-producing bacteria of the gut microbiome and muscle mass, strength and function. In this cross-sectional study, $n=490$ men (64.4 \pm 13.5 years) from the Geelong Osteoporosis Study provided food frequency questionnaire data, from which the Australian Recommended Food Score (ARFS) and Dietary Inflammatory Index (DII) score were calculated. Muscle mass (skeletal muscle index from DXA-derived lean mass), muscle strength (handgrip strength) and muscle function (Timed Up-and-Go test) were measured. Participants provided stool samples for $16 \mathrm{~S}$ rRNA gene sequencing. There was no evidence of associations between alpha or beta diversity and muscle health measures. A healthier ARFS score was positively associated with the relative abundance of butyrate-producing bacteria $(\beta 0.09$, $95 \%$ CI $0.03,0.15$ ) and a higher (pro-inflammatory) DII score was associated with lower relative abundance of butyrate-producing bacteria $(\beta-0.60,95 \% \mathrm{CI}-1.06,-0.15)$. The relative abundance of butyrate-producing bacteria was positively associated with healthier muscle mass, strength and function; however, these relationships were attenuated in multivariable models. These findings support the role of diet quality in achieving a healthier gut microbiome, however, further evidence is required for a gut-muscle axis in humans.
\end{abstract}

Keywords: Microbiome; diet quality; muscle health; Sarcopenia; butyrate

(C) The Author(s), 2021. Published by Cambridge University Press on behalf of The Nutrition Society. This is an Open Access article, distributed under the terms of the Creative Commons Attribution-NonCommercial-ShareAlike licence (http://creativecommons.org/licenses/by-nc-sa/4.0/), which permits non-commercial re-use, distribution, and reproduction in any medium, provided the same Creative Commons licence is included and the original work is properly cited. The written permission of Cambridge University Press must be obtained for commercial re-use. 


\section{Introduction}

Alterations in the gut microbiome have been implicated in systemic conditions related to poor muscle health, such as frailty and obesity (Ticinesi et al., 2017). Based on findings in animal and human studies a gut-muscle-axis has been proposed, suggesting that bacteria in the gut and/or their associated metabolites play a role in regulating muscle health (Grosicki et al., 2018). Given the impact that diet has on the gut microbiome and muscle health, diet is a likely contributor to the gut-muscle-axis (Donovan, 2017).

Evidence for a role of the gut microbiome in muscle health has emerged from both human and animal studies. Germ-free mice demonstrate reduced skeletal muscle mass and muscle function, with muscle mass returning to normal levels following inoculation with faecal microbiome from wild-type mice (Lahiri et al., 2019). Prebiotic and probiotic supplementation in wild-type mice has also resulted in increased muscle mass, strength and changes in muscle fibre composition (Chen et al., 2016; Everard et al., 2011). In humans, a prebiotic fibre trial in older participants reported increased muscle strength (Buigues et al., 2016). An observational study also reports relationships between frailty and a greater abundance of Bacteroides and lower levels of beneficial metabolites (Claesson et al., 2012) and men with high and low muscle mass appear to differ in the abundance of several bacterial species in the gut microbiome (Barger et al., 2020). However, evidence of alpha-diversity (the bacterial diversity within individual participants) associating with muscle health is lacking (Barger et al., 2020).

While a dearth of evidence demonstrates mechanisms by which this gut-muscle-axis may function, one potential pathway is via the actions of short-chain fatty acids (SCFA), which are produced by certain bacteria of the gut microbiome (Morrison and Preston, 2016). Bacteria in the gut ferment non-digestible dietary fibres and the SCFAs, primarily acetate, propionate, and butyrate, are produced as byproducts (Ríos-Covián et al., 2016). Microbiome-derived butyrate has several distinct roles for the intestinal epithelium, being an energy source for colonocytes, regulating mucosal homeostasis and exerting antiinflammatory effects on the intestinal environment (Canani et al., 2011), functions which may have protective properties for gut conditions such as colon cancer and inflammatory bowel disease (Bach Knudsen et al., 2018; Couto et al., 2020). The anti-inflammatory role of butyrate is of interest in the gutmuscle-axis as peripheral inflammatory markers appear to play a causal role in age-related declines in muscle health (Michaud et al., 2013). A growing body of research suggests that systemic inflammation impacts muscle health at the level of both neural and muscle tissue, with pro-inflammatory cytokines interfering in processes including muscle protein synthesis and disposal of dysfunctional mitochondria (Salminen et al., 2012). Direct evidence for butyrate's role in regulation of muscle health is emerging. An observational study reported that men with higher muscle mass and fibre intake exhibited greater abundance of butyrate-producing bacteria compared to participants with the lowest muscle mass and fibre intake (Barger et al., 2020). An exercise trial reported increases in butyrate-producing bacteria, faecal butyrate levels, and lean mass in participants who were lean but not those with obesity (Allen et al., 2018). More compellingly, the recent NU-AGE trial, comprising a large-scale trial of a Mediterraneanstyle diet in older adults over one year, reported that the intervention changed microbiota composition, with an increased relative abundance of butyrate-producing bacteria. These microbiota changes were in turn associated with reduced frailty, including better muscle strength, as well as lower inflammatory markers (Ghosh et al., 2020).

Colonic butyrate levels can be modified by the diet (Flint, 2012), with fibre the preferred substrate for butyrate-producing bacteria. In indirect evidence for butyrate's role in muscle health, fibre supplementation has increased muscle mass in mice (Cani et al., 2009), and increased glucose metabolism in human muscle tissue (Robertson et al., 2012). Rather than measuring fibre intake, higher scores on various diet quality indices also have associated with increased SCFAs and muscle health improvements (Davis et al., 2021; Ruiz-Saavedra et al., 2020), potentially due to cross-feeding by members of the gut microbiome (Rivière et al., 2016). Diet quality indices can provide a measure of adherence to dietary guidelines, dietary diversity, nutritional recommendations for management of health conditions, or functional outcomes.

The role of diet quality in the abundance of butyrate-producing bacteria is yet to be investigated. Although there is evidence from a pre-clinical trial of butyrate attenuating declining muscle health 
through its anti-inflammatory properties (Walsh et al., 2015), and evidence from human trials suggesting that improvements in diet quality can positively influence strength via changes to the gut microbiota (Ghosh et al., 2020), population studies assessing the association between butyrate-producing bacteria and muscle health are lacking. The current study aims to assess the relationships between diet quality, butyrate-producing bacteria, and muscle health in a large cohort of randomly selected Australian men. We hypothesised that (1) diet quality increases would be accompanied by increases in the relative abundance of butyrate-producing bacteria, and (2) bacterial diversity and the relative abundance of butyrate-producing bacteria would be positively associated with measures of muscle health.

\section{Methods}

\section{Study design and participants}

This cross-sectional study utilised data from the Geelong Osteoporosis Study (GOS), a prospective cohort study that has been collecting men's data since 2001. Details regarding participant recruitment, data collection and participation rates have been published previously (Pasco et al., 2012). In brief, participants were randomly identified from the electoral roll for the Barwon Statistical Division in SouthEastern Australia and invited to participate. The current study is based on data from the GOS men's 15-year follow-up, conducted from 2016 to 2020. Inclusion criteria for the entire GOS cohort (men and women) was a listing on the electoral roll for the Barwon Statistical Division, and exclusion criteria were residence in the region for $<6$ months and inability to provide written informed consent. Inclusion criteria for the current study included the supply a stool samples and at least one concurrent measure of muscle health including handgrip strength (HGS), dual-energy X-ray absorptiometry (DXA) lean mass and/or Timed Up-and-Go (TUG) test. Of the $n=625$ men who completed the 15 -year follow-up assessments, $n=490$ (78 \%) fulfilled these criteria. Of these, five were excluded due to use of a colostomy bag $(n=1)$, prior colon surgery $(n=1)$, unidentifiable samples $(n=2)$ and one identified as a second sample submitted by a participant. Written, informed consent was provided by all participants and approval was provided by the Human Research Ethics Committee at Barwon Health.

\section{Muscle health measures}

\section{Muscle mass}

Body composition data were collected from whole-body DXA using a densitometer (Lunar Prodigy-Pro, LUNAR Corporation, Madison, WI). From these, appendicular lean mass was used as a surrogate measure for skeletal muscle mass, which provided the muscle data to calculate skeletal muscle index (SMI) $\left(\mathrm{kg} / \mathrm{m}^{2}\right)$. The cut-off value for low SMI was $<7.0 \mathrm{~kg} / \mathrm{m}^{2}$, aligning with the 2019 European Working Group on Sarcopenia in Older People (EWGSOP2) guidelines for low muscle quantity for men (CruzJentoft et al., 2019).

\section{Muscle strength}

HGS was employed as an indicator of muscle strength (Roberts et al., 2011). A hand-held dynamometer (Vernier, LoggerPro3, Beaverton, OR) was used to measure handgrip, with participants seated and holding the dynamometer with the elbow flexed at $90^{\circ}$. Participants squeezed the dynamometer for several seconds on both sides, and the maximum reading for each hand was recorded. The values used herein are the mean of these two maximal values. The cut-off value for low muscle strength was identified as $<27 \mathrm{~kg}$, as per EWGSOP2 guidelines for low muscle strength in men (Cruz-Jentoft et al., 2019).

\section{Muscle function}

Muscle function was measured with the TUG test (Richardson, 1991), which times participants in seconds as they rise from a seated to a standing position without the use of arm rests, walk $3 \mathrm{~m}$, turn 
around and walk back to their original standing position, before sitting down. This test is performed without the use of the upper body, unless the participant requires a walking aid. The cut-off value for poor muscle function was identified as $\geq 20$ seconds, as per EWGSOP2 guidelines for low muscle performance (Cruz-Jentoft et al., 2019).

\section{Microbiome analysis}

At GOS appointments, participants were invited to provide a stool sample using the Omnigene ${ }^{\circledR} \bullet$ gut stool home collection kit (DNA Genotek, Ottawa, ON). The kit contained a nucleic acid stabilisation liquid and, after the sample was collected and mixed by the participant, it was returned to the research centre via reply-paid post. Upon receipt, samples were aliquoted and stored at $-80^{\circ}$ within 24 hours. Microbial genomic DNA was extracted from the stool aliquot using the QIAamp Fast DNA Stool Mini Kit (QIAGEN, Manchester, UK). Extractions were conducted according to manufacturer's guidelines, with an additional mechanical lysis step using PowerBead tubes (Cat No 13123, QIAGEN). DNA quality and quantity were assessed using the Nanodrop 1000 (Thermo Scientific). Samples were diluted to concentrations of $10 \mathrm{ng} / \mu \mathrm{L}$ and freighted to the Australian Genomic Research Facility for $16 \mathrm{~S}$ rRNA gene sequencing and taxonomic assignment.

\section{Sequence read processing}

The V3-V4 region of the $16 \mathrm{~S}$ rRNA gene was amplified by polymerase chain reaction using 341-Forward and 806-Reverse primers. Sequencing was conducted using the Illumina MiSeq platform. Bioinformatic processing was performed with QIIME 2019.7 (Bolyen et al., 2019). The demultiplexed raw reads were primer trimmed and quality filtered using the cutadapt plugin followed by denoising with DADA2 (Callahan et al., 2016) (via q2-dada2). Taxonomy was assigned to amplicon sequence variants (ASV) using the classify-sklean method from the feature-classifier plugin (Bokulich et al., 2018) using naïve Bayes classifier. Sequence reads were 12,572-378,206 reads per sample, and a mean read count of 67,429. ASVs were then matched to the SILVA database to identify the phylum, class, order, family, genus and species (where available). A preliminary batch of $n=161$ samples from this cohort was originally sequenced and analysed in 2017 (Davis et al., 2020). In the current study the sequence reads from these $n=161$ samples were re-analysed for ASV taxonomic distribution and matched to the SILVA database, along with the remaining $n=329$ samples. Quality control samples from the original and second batches were included in final sequencing to ensure good reproducibility.

Microbiome data pre-processing was conducted in line with recommendations from Callahan et al. (2016). In brief, zero count ASVs, uncharacterised taxa, and non-bacterial taxa such as chloroplast and mitochondria were removed. For beta diversity and butyrate analyses, low prevalence taxa present in less than $1 \%$ of samples were removed.

\section{Alpha and beta diversity}

Alpha-diversity was assessed by the Shannon Index and Observed taxa metrics. The Shannon Index is a measure of both richness and evenness of taxa, while Observed taxa is a count of unique ASVs in each sample. Beta diversity analyses compared the microbial community structure between groups dichotomised as high/low for SMI, TUG and HGS. Beta diversity was quantified with both weighted and unweighted UniFrac distances, and a permutational analysis of variance (PERMANOVA) was performed utilising 999 permutations. Clustering was visually inspected using principal coordinates analysis.

\section{Relative abundance of butyrate-producing bacteria}

Due to limitations in database species identification following $16 \mathrm{~S}$ sequencing, butyrate-producing bacteria were identified a priori from details of SCFA measures in in vitro bacterial cultures (Alessi et al., 2020; Barcenilla et al., 2000; Duncan et al., 2002; Holmstrøm et al., 2004; Louis et al., 2004; 
Reichardt et al., 2014; Schwiertz et al., 2002; Shetty et al., 2018), and then confirmed through details provided by Bergey's Manual of Systematics of Archaea and Bacteria (Whitman and John Wiley \& Sons, 2015). The bacteria identified as butyrate-producing were Faecalibacterium prausnitzii, Subdoligranulum variabile, Anaerobutyricum hallii, Anaerostipes caccae, Anaerostipes hadrus, Coprococcus catus, Clostridium sp., Coprococcus sp., Eubacterium rectale, Roseburia faecis, Roseburia intestinalis and Roseburia inulinivorans. These species were agglomerated to the genus level and subsequently combined to form a composite variable comprising the relative abundance of all genera combined for a total relative abundance of butyrate-producing bacteria. These values were centre log-ratio (CLR) transformed to account for the compositional nature of microbiome data (Gloor et al., 2017).

\section{Dietary data}

The Australian Cancer Council's Dietary Questionnaire for Epidemiological Studies (DQES) was used to collect dietary data; this questionnaire has been validated in a similar population (Giles and Ireland, 1996). The DQES collects information on quantity and frequency of consumption of 74 foods and six alcoholic beverages in the preceding 12 months.

\section{A priori diet quality scores}

The Australian Recommended Food Score (ARFS) and the Dietary Inflammatory Index (DII@) were calculated from the DQES to measure diet quality. The ARFS provides a diet quality score based on components of the 2008 Australian Dietary Guidelines, and therefore quantifies adherence to these guidelines. Points are awarded for consumption of (1) vegetables, nuts, and beans, (2) fruit, (3) protein containing foods, (4) grains, (5) dairy, (6) fats, and (7) alcohol, the total of which provides the participant's ARFS, with scores ranging from a theoretical 0 to 74 (Collins et al., 2015). The DII, in contrast, measures the inflammatory potential of the diet and includes up to 45 food and nutrition components (Shivappa et al., 2013). The DQES provides only 22 of these components; so, the DII score used herein has been modified by the original authors to reflect the effect of these 22 components. The DII is based on an exhaustive literature search resulting in 45 components directly associated with changes in inflammatory biomarkers. DII scores range from a theoretical -8.87 to +7.98 , with a positive score reflecting a pro-inflammatory diet and a negative score reflecting an anti-inflammatory diet. The ARFS and DII have both been validated in similar populations (Collins et al., 2015; Tabung et al., 2015).

\section{Potential confounding variables}

Extensive demographic, lifestyle and medical data were collected for consideration as potential confounders. Area-based socio-economic status was measured with the Index of Relative Socio-economic Advantage and Disadvantage, which accounts for social and economic circumstances for both participants and their households and is considered a measure of both relative advantage and disadvantage. Other variables considered included DXA whole-body fat mass (g), self-reported age, ethnicity, education (never attended school, primary school, some secondary school, completed secondary school, TAFE/trade/apprenticeship, university or other post-secondary qualification) and current smoking status. Self-reported physical activity (PA) level was quantified through administration of Baecke's Physical Activity Questionnaire (BPAQ) (Baecke et al., 1982). The BPAQ is a Likert scale of PA during work, sport, and leisure time, and these three scores were combined for a total PA score. A Likert scale was also used for self-reported presence of stomach symptoms (nausea, gas or indigestion), and intestinal symptoms (constipation, loose bowels or diarrhoea). These responses were then collated to create variables for presence of stomach symptoms and/or intestinal symptoms.

A composite, binary variable was developed for self-reported current medical conditions that may affect muscle health, including osteoarthritis, rheumatoid arthritis, hypoglycaemia, Parkinson's disease, multiple sclerosis, emphysema, chronic bronchitis, other lung disease, chronic fatigue syndrome, 
anaemia and pernicious anaemia. A similar composite variable was also developed based on selfreported medical conditions that may affect the gut, including chronic gastritis, hiatus hernia/oesophageal reflux, peptic ulcer disease, gastric surgery, anorexia nervosa, bulimia, bowel surgery, malabsorption, chronic diarrhoea, irritable bowel syndrome, inflammatory bowel disease and coeliac disease.

A composite, binary variable was developed for current use of medications that may affect muscle, which included anti-rheumatoid agents, muscle relaxants, neuromuscular agents, adrenal steroid, gonadal, and pituitary hormones, insulin preparations, hypoglycaemic agents and anabolic agents. A composite variable of medications that may affect the gut included reflux medications, laxatives, antidiarrheals, digestive supplements, hypoglycaemic agents, antibiotics, narcotic analgesics and antipsychotic and antidepressant medications in light of their well-documented effect on the human gut (Maier and Typas, 2017).

Important contributing factors were identified using causal directed acyclic graphs, and minimum adjustment sets were generated for each hypothesis (Supplementary Figures S1 and S2). Potential confounders included in the diet quality and butyrate-producing bacteria model included age, smoking, PA, medications that may affect the gut, and intestinal symptoms. The models investigating (1) alphaand beta-diversity -muscle health and (2) butyrate producing bacteria-muscle health relationships included adjustment for age, smoking, the ARFS, DII, PA, medical conditions that may affect the gut and medical conditions that may affect muscle health. Potential confounding variables were then verified using correlation matrices (Supplementary Table S2). Batch effects were also added to both models to account for any impact of the two sequencing batches.

\section{Statistical analyses}

Linear regression was used to assess the relationships between (1) diet quality and butyrate producers, (2) alpha-diversity and muscle health outcomes, and (3) butyrate producers and muscle health outcomes. Collinearity between independent and dependent variables and demographics, health, and lifestyle factors were further investigated using a correlation matrix (Supplementary Table S2). Correlations between variables were tested using Pearson's test for continuous variables, Spearman's for categorical variables and point-biserial for a combination of continuous, categorical or binary variables. Deviation from model assumptions, including normal distribution of residuals, was visually inspected including residuals versus fits plot to detect non-linearity, unequal error variances, and outliers, and normal Q-Q plot, and correlation coefficients were used to assess potential collinearity. Significance was set at $p<0.05$.

Exploratory analyses were conducted with data-driven definitions for muscle health categories. SMI was categorised into tertiles due to its normal distribution. HGS and TUG scores were skewed; thus high/ low HGS was dichotomised at $45 \mathrm{~kg}$, and high/low TUG dichotomised at 10 seconds, which were the values at which the distribution visually dropped (Supplementary Figure S3). These data-driven cut-offs were applied in exploratory analyses for beta diversity. Levene's test for homogeneity of variance was conducted following any significant findings for beta-diversity. Further exploratory age-stratified analyses also were conducted, with age dichotomised at the mean $(<64.4$ years and $\geq 64.4$ years).

Analyses were conducted using R (version 3.6.3; R Core Team, 2013), and microbiome analyses were done using the phyloseq (version 1.30.0) package (McMurdie and Holmes, 2013). The analysis plan was preregistered at Open Science Framework (https://osf.io/6wsfe). Deviations from this preregistration included the use of Observed instead of Chaol taxa metrics for alpha-diversity. This was due to filtering of singletons during bioinformatic processing, which rendered the Chaol index estimate unreliable. A composite measure of butyrate-producing bacteria identified at genus level was used, since they were not consistently identified to species level. Additional exploratory analyses included beta-diversity using data-driven cut-off scores for muscle health outcomes, and investigation of age interaction in regression models. 


\section{Results}

\section{Participant characteristics}

Participant characteristics are summarised in Table 1. Participants were men and had an age range of $33-$ 96 years with a mean $64.4 \pm 13.6$ years, and were all educated at least to primary school level, with $51.3 \%$ currently working and $42.5 \%$ retired. The majority were current non-smokers, approximately half were taking medications that may impact the gut microbiome, and 37 and $44 \%$ of participants had medical conditions that may affect the gut microbiome or muscle health, respectively. Very few had low muscle mass (SMI $<7.0 \mathrm{~kg} / \mathrm{m}^{2}, 6.0 \%$ ), strength (HGS $<27 \mathrm{~kg}, 2.1 \%$ ) or function (TUG $\geq 20$ seconds, $1.2 \%$ ) as defined by the pre-defined clinical cut-offs. The ARFS ranged from 7 to 55 , with the median slightly below the mid-point ( 31 from a potential total of 71), and the DII scores ranged from -2.92 to +2.53 with a median of 0.18 .

Compared to the current study sample, participants who completed the GOS 15-year follow-up assessment, but did not provide stool samples, were younger, with a median age of 54 years. A similar proportion had low SMI (6.3\%), but a marginally greater proportion had low HGS (7.4\%) and slow TUG time (3.2\%) compared to the current sample. Median ARFS scores were similar (30, IQR 25, 35) and DII scores were marginally more pro-inflammatory $(0.25$, IQR $-0.74,1.20)$ when compared to the current sample.

\section{Butyrate-producing bacteria}

All genera of butyrate-producing bacteria included in the composite variable were members of the Clostridiales order, with two from the Ruminococcaceae family, four from Lachnospiraceae, and the genus with the lowest counts was from the Eubacteriaceae family. The taxonomy and median relative abundance for each of the individual genera are summarised in Table 2.

\section{Associations between diet quality indices and butyrate-producing bacteria}

Both a healthy ARFS and an anti-inflammatory diet (as defined by a negative DII score) were associated with increased relative abundance of butyrate-producing bacteria (Table 3 and Figure 1). An increase of one point on the ARFS was associated with a 0.12 increase in the CLR transformed relative abundance of butyrate-producing bacteria $(95 \% \mathrm{CI} 0.07,0.18)$, and the overall model fit was $R^{2}=0.03$. A one-point decrease on the DII (ie less inflammatory diet), was associated with a 0.80 increase in the CLR transformed relative abundance of butyrate-producing bacteria $(95 \% \mathrm{CI}-1.27,-0.34)$, with an overall model fit of $R^{2}=0.02$. These associations were retained following adjustment for age, smoking, PA, medications that may affect the gut, intestinal symptoms, and potential batch effects [ARFS $(\beta 0.09,95 \%$ CI $0.03,0.15)$, DII $(\beta 0.60,95 \%$ CI $-1.06,-0.15)]$. The overall model fit for both the ARFS and DII adjusted models was $R^{2}=0.11$.

\section{S rRNA bacterial diversity}

The most common phylum present in the gut microbiome was Firmicutes (relative abundance $54.5 \% \pm$ SD $0.2 \%)$, followed by Bacteroidetes $(37.4 \% \pm 0.2 \%)$, Proteobacteria $(5.3 \% \pm 0.1 \%)$, Verrucomicrobia $1.3 \%(0.0 \%)$, and Actinobacteria $0.7 \%(0.0 \%)$. No differences in alpha-diversity were observed (Shannon Index or Observed taxa) for continuous measures of SMI, HGS or TUG (Supplementary Figure S4 and Supplementary Table S1). Similarly, there was no distinct clustering for beta diversity in the low versus high categories for SMI or TUG. However, there was weak evidence of a difference between low and high HGS groups in unadjusted models for unweighted UniFrac distance $(p=0.081)$ (Supplementary Figure S5). There was no evidence of differences in multivariate dispersion (variance) between the groups $[F(1,482)=0.73, p=0.40]$. 
Table 1. Study sample characteristics.

\begin{tabular}{|c|c|}
\hline & Participants $(n=485)$ \\
\hline Age, years, mean $( \pm S D)$ & $64.4(13.6)$ \\
\hline \multicolumn{2}{|l|}{ Education $^{a}$} \\
\hline Primary or some secondary school, $n(\%)$ & $118(24.5)$ \\
\hline Completed secondary or vocational training, $n(\%)$ & $200(41.0)$ \\
\hline Tertiary education, $n(\%)$ & $166(34.5)$ \\
\hline \multicolumn{2}{|l|}{ Employment } \\
\hline Working, $n(\%)$ & $249(51.3)$ \\
\hline Not working, $n(\%)$ & $9(1.9)$ \\
\hline Home duties, $n(\%)$ & $4(0.8)$ \\
\hline Student, $n(\%)$ & $3(0.6)$ \\
\hline Retired, $n(\%)$ & $206(42.5)$ \\
\hline Unable to work, $n(\%)$ & $6(1.2)$ \\
\hline Not applicable, $n(\%)$ & $8(1.7)$ \\
\hline PA score, median (IQR) & $6.0(5.0,8.0)$ \\
\hline Current smoker, $n(\%)$ & $30(6.2)$ \\
\hline Medications that may affect the gut, $n(\%)$ & $222(45.8)$ \\
\hline Medications that may affect muscle, $n(\%)$ & $54(11.1)$ \\
\hline Medical conditions that may affect the gut, $n(\%)$ & $179(36.9)$ \\
\hline Medical conditions that may affect muscle, $n(\%)$ & $211(43.5)$ \\
\hline Body fat (kg), median (IQR) & $24.4(18.8,31.5)$ \\
\hline SMI $\left(\mathrm{kg} / \mathrm{m}^{2}\right)$, mean $( \pm \mathrm{SD})$ & $8.5(0.9)$ \\
\hline Low SMI <7.0 kg/m², $n(\%)$ & $29(6.0)$ \\
\hline HGS (kg), median (IQR) & $38.4(32.9,43.1)$ \\
\hline Low HGS <27 kg, $n(\%)$ & $10(2.1)$ \\
\hline TUG (seconds), median (IQR) & $8.6(7.6,9.9)$ \\
\hline Slow TUG $\geq 20$ seconds, $n(\%)$ & $6(1.2)$ \\
\hline ARFS, mean $( \pm S D)$ & $31.2(9.4)$ \\
\hline DII, median (IQR) & $0.18(-0.77,1.10)$ \\
\hline Energy intake (kJ/d), median (IQR) & $7,652(6,075,9,501)$ \\
\hline Daily protein (g/day), median (IQR) & $88.5(68.0,110.4)$ \\
\hline
\end{tabular}

Note: $n=485$

Abbreviations: ARFS, Australian Recommended Food Score; DII, Dietary Inflammatory Index; HGS, handgrip strength; PA, physical activity; SMI, Skeletal Muscle Index; TUG, Timed Up-and-Go.

${ }^{a} n=1$ missing data. 
Table 2. Relative abundance of butyrate producing bacteria.

\begin{tabular}{lc}
\hline Taxonomy & Relative abundance (IQR) \\
\hline Firmicutes; Clostridia; Clostridiales; Ruminococcaceae; Faecalibacterium & $9.6 \%(4.8,18.1)$ \\
\hline Firmicutes; Clostridia; Clostridiales; Ruminococcaceae; Subdoligranulum & $1.3 \%(0.6,2.7)$ \\
\hline Firmicutes; Clostridia; Clostridiales; Lachnospiraceae; Roseburia & $2.2 \%(1.1,3.6)$ \\
\hline Firmicutes; Clostridia; Clostridiales; Lachnospiraceae; Coprococcus 2 & $0.2 \%(0.0,1.1)$ \\
\hline Firmicutes; Clostridia; Clostridiales; Lachnospiraceae; Anaerostipes & $0.2 \%(0.1,0.4)$ \\
\hline Firmicutes; Clostridia; Clostridiales; Lachnospiraceae; Coprococcus 3 & $0.1 \%(0.1,0.2)$ \\
\hline Firmicutes; Clostridia; Clostridiales; Eubacteriaceae; Eubacterium & $0 \%(0.0,0.0)$ \\
\hline
\end{tabular}

Table 3. Linear regression results for the Australian Recommended Food Score and the Dietary Inflammatory Index and associations with butyrate producing bacteria.

\begin{tabular}{|c|c|c|c|}
\hline & $\beta$ & $95 \% \mathrm{Cl}$ & $R^{2}$ \\
\hline \multicolumn{4}{|c|}{ Australian Recommended Food Score } \\
\hline Model 1 & $0.12^{* *}$ & $0.07,0.18$ & 0.03 \\
\hline Model 2 & $0.09^{*}$ & $0.03,0.15$ & 0.11 \\
\hline \multicolumn{4}{|c|}{ Dietary Inflammatory Index } \\
\hline Model 1 & $-0.80^{\star *}$ & $-1.27,-0.34$ & 0.02 \\
\hline Model 2 & $-0.60^{\star}$ & $-1.06,-0.15$ & 0.11 \\
\hline
\end{tabular}

Note: Model 1 unadjusted, Model 2 adjusted for age, gut medications, intestinal symptoms, PA, smoking and batch effects.

${ }^{*} p<0.05$

${ }^{* *} p<0.001$.

Due to the very small numbers in the low-muscle-health grouping, additional exploratory analyses were performed utilising data-driven cut-off points for muscle health. These showed no evidence of beta diversity clustering between SMI or HGS categories. Furthermore, the weak difference observed between high/low HGS groups with the original cut-offs was not strengthened with data-derived cutoffs. However, while no clustering was evident visually in principal coordinates analysis, a significant difference was found between high- and low-TUG participants in unadjusted models [unweighted UniFrac distance, PERMANOVA, Sum of squares (SS) $=0.42, R^{2}=0.005, p=0.003$, weighted UniFrac distance, PERMANOVA, SS $\left.=0.22, R^{2}=0.005, p=0.011\right]$. Multivariate dispersion did not differ between groups $[F(1,479)=0.20, p=0.65]$.

\section{Associations between butyrate-producing bacteria and muscle mass, strength and function}

In unadjusted models, higher relative abundance of butyrate-producing bacteria was positively associated with better measures of SMI and HGS, and shorter times for TUG. For every unit increase in CLR transformed butyrate-producing bacteria, SMI increased by $0.02 \mathrm{~kg} / \mathrm{m}^{2}$ (overall model fit $R^{2}=0.03$ ), HGS increased by $0.003 \mathrm{~kg} \mathrm{~m}^{2}$ (overall model fit $R^{2}=0.05$ ), and TUG time reduced by -0.003 seconds $\mathrm{m}^{2}$ with an overall model fit $R^{2}=0.03$ (all $p<0.001$ ). All associations were attenuated slightly following adjustment for covariates (Table 4 ).

A potential age interaction for HGS, or TUG, was further explored with age-stratified at $<64.4$ years and $\geq 64.4$ years for HGS and TUG. However, no age interaction was evident, with similar coefficients between the age groups for each of the muscle outcomes (Supplementary Figure S6). 

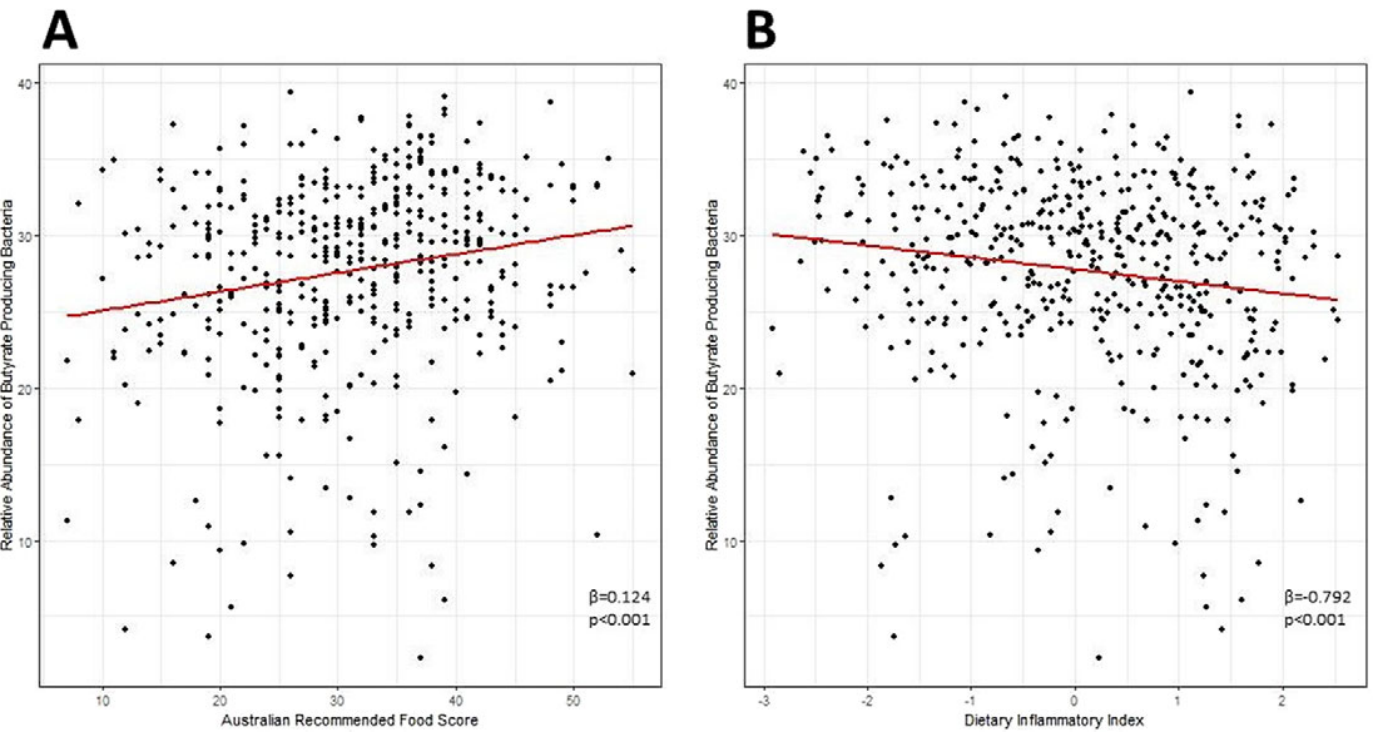

Figure 1. Associations between diet quality indices and the relative abundance of butyrate producing bacteria. (A) The Australian Recommended Food Score is positively associated with the relative abundance of butyrate producing bacteria $[0.12(95 \% \mathrm{Cl} 0.07$, $0.18)$ ], and (B) the Dietary Inflammatory Index is negatively associated with the relative abundance of butyrate producing bacteria $[-0.80(95 \% \mathrm{Cl}-1.27,-0.34)]$.

Table 4. Regression results for associations between butyrate-producing bacteria and muscle mass, strength and function outcomes.

\begin{tabular}{|c|c|c|c|c|}
\hline & $\beta$ & $95 \% \mathrm{Cl}$ & $R^{2}$ & Covariates found to attenuate the relationship \\
\hline \multicolumn{5}{|c|}{ Skeletal muscle index } \\
\hline Model 1 & $0.02^{*}$ & $0.01,0.04$ & 0.03 & \\
\hline Model 2 & 0.01 & $-0.01,0.02$ & 0.30 & ARFS (diet quality) and PA \\
\hline \multicolumn{5}{|c|}{ Handgrip strength (log10 transformed) } \\
\hline Model 1 & $0.01^{*}$ & $0.004,0.009$ & 0.05 & \\
\hline Model 2 & 0.002 & $-0.0001,0.004$ & 0.37 & Age, PA and muscle medical conditions \\
\hline \multicolumn{5}{|c|}{ Timed Up-and-Go (log10 transformed) } \\
\hline Model 1 & $-0.01^{*}$ & $-0.01,-0.004$ & 0.03 & \\
\hline Model 2 & -0.003 & $-0.01,0.00$ & 0.37 & Age \\
\hline
\end{tabular}

Note: Model 1 unadjusted, Model 2 adjusted for age, fat mass, Australian Recommended Food Score, gut medical condition, muscle medical condition, PA, smoking and batch effects.

${ }^{*} p<0.001$.

\section{Discussion}

The current study investigated the relationships between diet, butyrate-producing bacteria and muscle mass, strength and function in a group of Australian men. We showed that a healthy ARFS score and an antiinflammatory diet were positively associated with the relative abundance of butyrate-producing bacteria. There was also weak evidence for differences in beta-diversity of those with high and low muscle strength. While a higher relative abundance of butyrate-producing bacteria was associated with better measures of all muscle indices, the effect sizes were small and the relationships were marginally attenuated after adjustment. 
Our findings that measures of diet quality - a healthy Australian and an anti-inflammatory diet were related to an increased abundance of butyrate-producing bacteria supports previous work in this area. A study investigating the ARFS and the gut microbiome (Harbison et al., 2021) reported that a healthier ARFS was associated with the relative abundance of members of the Bacteroides and Lachnospiraceae genera, and that these abundances differed between healthy controls and participants with type 1 diabetes mellitus. Diet quality has also been associated with higher concentrations of SCFA and/or greater abundance of bacterial species related to desirable health outcomes, such as Akkermansia muciniphila and Lactobacillus (Ruiz-Saavedra et al., 2020). Ruiz-Saavedra et al. also reported that, in addition to other diet quality indices, the DII was associated with the abundance of Faecalibacterium praunsnitzii, a well-established butyrate-producer. This bacterial species, along with other butyrate producers, was also increased by a one-year Mediterranean-style diet in older adults of the NU-AGE study (Ghosh et al., 2020). Our study supports these findings, and those from Zheng et al., which found that a pro-inflammatory diet was associated with greater abundance of bacterial species considered either pathogenic or associated with pro-inflammatory biomarkers (Zheng et al., 2020).

The range of fibre-rich plant foods present in a healthy diet may explain the positive associations we observed between diet quality and butyrate-producing bacteria. Dietary fibre is metabolised by several members of the bacterial microbiome. These primary degraders breakdown fibre from complex polysaccharides to mono- or oligosaccharides, which are fuel for butyrate producing bacteria (Baxter et al., 2019). While the current study focused on the relative abundance of butyrate-producing bacteria, future research may benefit from the inclusion of primary fibre degraders to account for this cross-feeding between bacteria (Soto-Martin et al., 2020). In addition to fibre, a higher ARFS score may also reflect greater dietary diversity, indicating consumption from several food groups. Dietary diversity is associated with bacterial diversity (McDonald et al., 2018), which is in turn related to better health outcomes (Claesson et al., 2012). Dietary diversity increases the likelihood of exposure to a wider array of nutrients that may contribute to the complex, symbiotic community of bacteria associated with butyrate production (Tavakoli et al., 2016). Thus, elucidating the potential role of dietary diversity that is inherent in all diet quality indices, independent of fibre consumption, in the diet quality-butyrate-producing bacteria relationship may also be beneficial. In addition to the known anti-inflammatory effects of fibre (Shivappa et al., 2013), the inflammatory potential of overall diet, which is measured by the DII, also may play a role in the relative abundance of butyrate producers. Other food components of the DII have been observed to contribute to the gut microbiota composition, including alcohol, fat type and quantity, and protein (Bishehsari et al., 2017; Wu et al., 2011). However, it is likely that no single component decides the inflammatory effect of diet in the gut, and more likely is the interplay between these components, helping or hindering the environment in which butyrate-producing bacteria can thrive.

Consistent with reports from previous studies that investigated alpha-diversity and frailty and lean mass in humans (Barger et al., 2020; Zhang et al., 2020), we did not observe associations between alphadiversity and muscle health. Furthermore, the evidence for an association between greater abundance of butyrate-producing bacteria and healthier muscle mass, strength, and function was weakened following inclusion of covariates. The associations observed in unadjusted models were variably attenuated by age, physical activity, diet quality and muscle-related medical conditions, indicating complex relationships between a number of inter-related variables. While there is a dearth of evidence in humans investigating the relationship between butyrate and muscle health, Barger et al. (2020) reported associations between greater muscle mass and both butyrate-producing bacteria and butyrate production genes. However, while we observed attenuations in significance for all three muscle outcomes, associations reported by Barger et al. withstood adjustment. This may be because Barger et al. did not adjust for gut or muscle medical conditions, which the current study did. This discrepancy in findings may be further explained by the age range of 33-96 years in the current study compared to the $>65$ years inclusion criteria for Barger et al. Indeed, age was responsible for attenuating the relationships between butyrate-producing bacteria and muscle strength and function in the current study, however no age interaction was observed. 
In the current study age attenuated the butyrate-producing bacteria and muscle relationship for strength and function, but not mass. This may be due to age-related declines of the neurological component of muscle function which precede the physical manifestations (ie. mass) (McGregor et al., 2014). Furthermore, age-related changes in body composition cause intermuscular adipose infiltration, resulting in muscle quality degradation prior to reductions in muscle mass (Addison et al., 2014). Age is also associated with changes in the gut microbiome, including reduced abundance of certain beneficial bacteria and alpha-diversity (Jackson et al., 2016). However, it remains unclear whether these changes in the microbiome are due to chronological age itself or the dietary and lifestyle changes concomitant with age. Alterations in food intake and food preferences can occur as individuals age. These changes can impact peristalsis, which in turn can cause motility changes, altering the gut microbiome composition (Roager et al., 2016). Therefore, age also was considered in the relationship between diet quality and butyrate producers. Prebiotic, probiotic, or butyrate supplementation trials in older people may elucidate whether the impact of age on butyrate-producing bacteria could be circumvented, delivering potential benefits to muscle health.

Butyrate-producing bacteria directly influence the levels of intestinal butyrate (Pryde et al., 2002). While the current study did not observe an association between butyrate-producing bacteria and muscle health following adjustment, investigation in other study samples, such as women and very old participants ( $\geq 85$ years), may provide insight into this potential association across a wider range of people. A positive effect of butyrate-producing bacteria on muscle health may relate to butyrate's role in retaining muscle health with increasing age. In mice, butyrate supplementation appears to attenuate agerelated muscle atrophy (Walsh et al., 2015), and findings from a study of energy-restriction diets in pigs suggest that SCFA supplementation resulted in increased nitrogen retention, a marker of protein synthesis (Pacy et al., 1994). This suggests that increased butyrate concentration may help to attenuate muscle loss observed in energy-deficient diets, which are common in older age (Morley, 1997). The physiological mechanisms through which gut-derived butyrate may assist in muscle retention may be via healthy glucose and insulin measures. Supplemental butyrate has improved insulin measures in mice liver (Mollica et al., 2017), and in humans, fibre supplementation improved insulin measures in adipose tissue and muscle, independent of the liver (Robertson et al., 2012). These findings suggest that butyrate may improve the glucose disposal process, which is often hindered in older age (Ferrara et al., 2006), via either skeletal muscle and/or the liver. These potential glucose and insulin pathways and the limited systemic concentration of gut-derived butyrate (den Besten et al., 2013) warrant further investigation in humans.

\section{Strengths and limitations}

Data from this study were derived from the GOS, which is a well characterised, long-term population study. The wide range of data collection within the GOS allowed for several important covariates to be considered, including medications and medical conditions. In addition, the Baecke Physical Activity Questionnaire is a robust measure of work, leisure, and sport-related PA in older adults, which is an important consideration for muscle health research. However, this questionnaire has been validated only in participants aged $<60$ years and may therefore not accurately reflect the PA levels in older people. The use of DXA-derived SMI, HGS, and TUG provided objective measures for three important aspects of muscle health, and dietary assessment was conducted with a thorough and validated instrument. This study also reported a 78 per cent return rate of stool samples from the GOS cohort, suggesting good representation of the general community.

However, the cross-sectional nature of the study means that causality cannot be assumed. With few cases in all low muscle health categories, the current sample is considered a healthy one. Therefore, associations reported here may be more subtle than those detectable in a case-control study. Participants were men only and, considering differences in SCFA profiles have been observed between sexes 
(Sun et al., 2021), these results may not be applicable to women. Known limitations in the resolution of taxonomic identification in $16 \mathrm{~S}$ sequencing may have affected the identification of butyrate-producing bacteria. Self-reported dietary data are known to be associated with reporting biases and other sources of error (Shook et al., 2018). While all ARFS components were extractable from the FFQ, only 22 of the total 45 DII components were available. Therefore, the DII scores used herein may not have captured the full inflammatory potential of participants' diets (Phillips et al., 2019).

\section{Conclusions}

Healthier diet quality and an anti-inflammatory diet were positively associated with butyrate-producing bacteria in the gut microbiome. However, we did not observe compelling associations between either alpha-diversity, beta-diversity, or the relative abundance of butyrate-producing bacteria and muscle health. These findings support the role of diet quality in achieving a healthier gut microbiome, however, further evidence is required to support the presence of a gut-muscle axis in humans. Future research including human dietary interventions may assist to further elucidate the role of diet quality in muscle health and the potential mediating role of the gut microbiome.

Acknowledgements. We would like to thank the Geelong Osteoporosis Study participants and staff and acknowledge the support of the Deakin University IMPACT Institute. We thank Prof. Graham Giles of the Cancer Epidemiology Centre of The Cancer Council Victoria, for permission to use the Dietary Questionnaire for Epidemiological Studies (Version 2), Melbourne: The Cancer Council Victoria 1996.

Supplementary Materials. To view supplementary material for this article, please visit http://dx.doi.org/10.1017/gmb.2021.2.

Data availability statement. Data are available from the Geelong Osteoporosis Study Data Steering Committee upon reasonable request. Please direct enquiries to the corresponding author.

Author contributions. J.A.D. contributed to the conception of the study, conducted all analyses and drafted and revised all manuscript drafts following feedback from co-authors. F.C. contributed to the conception of the study, design of methodology, analysis of data, contributed to draft of the manuscript and revisions for the final version. M.M. assisted with analysis of data, contributed to draft of the manuscript and revisions for final version. J.A.P. assisted with data collection and provided feedback for manuscript revisions. N.S. provided calculations for the DII@ and provided feedback for manuscript revisions. J.R.H. provided access to the DII, technical expertise on its use and feedback for revisions. F.N.J. provided feedback for manuscript revisions. A.L. contributed to the conception of the study, design of methodology, analysis of data, contributed to draft of the manuscript and revisions for final version.

Funding. The Geelong Osteoporosis Study (GOS) was funded by the National Health and Medical Research Council (NHMRC) Australia (projects 299831 and 628582), the Geelong Region Medical Foundation, and Perpetual. The funding organisation played no role in the design or conduct of the study, in the collection, management, analysis and interpretation of the data, nor in the preparation, review and approval of the manuscript.

Disclosures. J.A.D. is supported by an Australian Government Research Training Program Scholarship. A.L. is supported by Deakin Dean's Postdoctoral Research Fellowship. J. R.H. owns controlling interest in Connecting Health Innovations LLC (CHI), a company that has licenced the right to his invention of the dietary inflammatory index (DIIC) from the University of South Carolina in order to develop computer and smart phone applications for patient counselling and dietary intervention in clinical settings. N.S. is an employee of CHI. The subject matter of this paper will not have any direct bearing on that work, nor has that activity exerted any influence on this project. F.N.J. has received: (1) competitive Grant/Research support from the Brain and Behaviour Research Institute, the National Health and Medical Research Council (NHMRC), Australian Rotary Health, the Geelong Medical Research Foundation, the Ian Potter Foundation and The University of Melbourne; (2) industry support for research from Meat and Livestock Australia, Woolworths Limited, the A2 Milk Company and Be Fit Foods; (3) philanthropic support from the Fernwood Foundation, Wilson Foundation, the JTM Foundation, the Serp Hills Foundation, the Roberts Family Foundation and the Waterloo Foundation; and (4) travel support and speakers honoraria from SanofiSynthelabo, Janssen Cilag, Servier, Pfizer, Network Nutrition, Angelini Farmaceutica, Eli Lilly and Metagenics. F.N.J. has written two books for commercial publication. J.A.P. has received speaker fees from Amgen, Eli Lilly and Sanofi-Aventis and funding from the NHMRC and MRFF, Barwon Health, Deakin University, Australia and New Zealand Bone and Mineral 
Society (ANZBMS), Amgen-GSK OA-ANZBMS, Amgen Australia, the BUPA Foundation, Osteoporosis Australia, the Geelong Community Foundation, the Western Alliance, the Norman Beischer Foundation and the Victorian COVID-19 Research Fund. M.M. has received Grant/research support from NHMRC, Deakin University School of Medicine, Deakin Biostatistics Unit, Institute for Mental and Physical Health and Clinical Translation and Medibank Health Research Fund. F.C. has no disclosures to report.

Notes on contributors. Jessica A. Davis is a PhD Candidate in the Food \& Mood Centre at IMPACT - Institute for Mental and Physical Health and Clinical Translation, Deakin University. Fiona Collier (PhD) is an Honorary Fellow at IMPACT - Institute for Mental and Physical Health and Clinical Translation, Deakin University. Mohammadreza Mohebbi is a biostatistician in the Biostatistics Unit at the Faculty of Health of Deakin University.

Julie A. Pasco (BSc(Hons), DipEd, PhD, MEpi) is Professor of Epidemiology at Deakin University and Barwon Health, Head of the Epi-Centre for Healthy Ageing, and Theme Leader for Population Health in IMPACT - Institute for Mental and Physical Health and Clinical Translation, in Geelong, Australia.Nitin Shivappa is a research assistant professor at University of South Carolina and a senior research scientist at Connecting Health Innovations, Columbia, SC USA.

James R. Hébert, Sc.D. is Health Sciences Distinguished Professor of Epidemiology in the Department of Epidemiology and Biostatistics and Director of the Cancer Prevention and Control Program at the University of South Carolina and President, Scientific Director, and Chair of the Department of Nutrition, Connecting Health Innovations LLC in Columbia, SC USA. Amy Loughman is a senior research fellow and leads the microbiome research stream at the Food \& Mood Centre, Deakin University.

Felice N. Jacka is Professor of Nutritional Psychiatry and Psychiatric Epidemiology and Director of the Food \& Mood Centre at Deakin University. She is also founder and president of the International Society for Nutritional Psychiatry Research.

\section{References}

Addison O, Marcus RL, Lastayo PC and Ryan AS (2014) Intermuscular fat: A review of the consequences and causes. International Journal of Endocrinology 2014, 309570. https://doi.org/10.1155/2014/309570

Alessi AM, Gray V, Farquharson FM, Flores-López A, Shaw S, Stead D, Wegmann U, Shearman C, Gasson M, CollieDuguid ESR, Flint HJ and Louis P (2020) $\beta$-Glucan is a major growth substrate for human gut bacteria related to Coprococcus eutactus. Environmental Microbiology 22(6), 2150-2164. https://doi.org/10.1111/1462-2920.14977

Allen JM, Mailing LJ, Niemiro GM, Moore R, Cook MD, White BA, Holscher HD and Woods JA (2018) Exercise alters gut microbiota composition and function in lean and obese humans. Medicine \& Science in Sports \& Exercise 50(4), 747-757. https://doi.org/10.1249/MSS.0000000000001495

Bach Knudsen K, Lærke H, Hedemann M, Nielsen T, Ingerslev A, Gundelund Nielsen D, Theil P, Purup S, Hald S, Schioldan A, Marco M, Gregersen S and Hermansen K (2018) Impact of diet-modulated butyrate production on intestinal barrier function and inflammation. Nutrients 10(10), 1499. https://doi.org/10.3390/nu10101499

Baecke JAH, Burema J and Frijters JER (1982) A short questionnaire for the measurement of habitual physical activity in epidemiological studies. The American Journal of Clinical Nutrition 36(5), 936-942. https://doi.org/10.1093/ajcn/36.5.936

Barcenilla A, Pryde SE, Martin JC, Duncan SH, Stewart CS, Henderson C and Flint HJ (2000) Phylogenetic relationships of butyrate-producing bacteria from the human gut. Applied and Environmental Microbiology 66(4), 1654-1661. https:// doi.org/10.1128/AEM.66.4.1654-1661.2000

Barger K, Langsetmo L, Orwoll ES and Lustgarten MS (2020) Investigation of the diet-gut-muscle axis in the osteoporotic fractures in men study. Journal of Nutrition, Health and Aging 24(4), 445-452. https://doi.org/10.1007/s12603-020-1344-1

Baxter NT, Schmidt AW, Venkataraman A, Kim KS, Waldron C and Schmidt TM (2019) Dynamics of human gut microbiota and short-chain fatty acids in response to dietary interventions with three fermentable fibers. MBio 10(1), e02566-e02518. https://doi.org/10.1128/mBio.02566-18

Bishehsari F, Desai V, Voigt RM, Forsyth CB and Keshavarzian A (2017) Alcohol and gut-derived inflammation. Alcohol Research 38(2), 163-171.

Bokulich NA, Dillon MR, Zhang Y, Rideout JR, Bolyen E, Li H, Albert PS and Caporaso JG (2018) q2-longitudinal: Longitudinal and paired-sample analyses of microbiome data. MSystems 3(6), e00219-18. https://doi.org/10.1128/ msystems.00219-18

Bolyen E, Rideout JR, Dillon MR, Bokulich NA, Abnet CC, Al-Ghalith GA, Alexander H, Alm EJ, Arumugam M, Asnicar F, Bai Y, Bisanz JE, Bittinger K, Brejnrod A, Brislawn CJ, Brown CT, Callahan BJ, Caraballo-Rodríguez AM, Chase J, Cope EK, Da Silva R, Diener C, Dorrestein PC, Douglas GM, Durall DM, Duvallet C, Edwardson CF, Ernst M, Estaki M, Fouquier J, Gauglitz JM, Gibbons SM, Gibson DL, Gonzalez A, Gorlick K, Guo J, Hillmann B, Holmes S, Holste H, Huttenhower C, Huttley GA, Janssen S, Jarmusch AK, Jiang L, Kaehler BD, Kang KB, Keefe CR, Keim P, Kelley ST, Knights D, Koester I, Kosciolek T, Kreps J, Langille MGI, Lee J, Ley R, Liu YX, Loftfield E, Lozupone C, Maher M, Marotz C, Martin BD, McDonald D, McIver LJ, Melnik AV, Metcalf JL, Morgan SC, Morton JT, Naimey AT, Navas-Molina JA, Nothias LF, Orchanian SB, Pearson T, Peoples SL, Petras D, Preuss ML, Pruesse E, Rasmussen LB, Rivers A, Robeson MS 2nd, Rosenthal P, Segata N, Shaffer M, Shiffer A, Sinha R, Song SJ, Spear JR, Swafford AD, Thompson LR, Torres PJ, 
Trinh P, Tripathi A, Turnbaugh PJ, Ul-Hasan S, Van der Hooft JJJ, Vargas F, Vázquez-Baeza Y, Vogtmann E, von Hippel M, Walters W, Wan Y, Wang M, Warren J, Weber KC, Williamson CHD, Willis AD, Xu ZZ, Zaneveld JR, Zhang Y, Zhu Q, Knight R and Caporaso JG (2019) Reproducible, interactive, scalable and extensible microbiome data science using QIIME 2. Nature Biotechnology 37(8), 852-857. https://doi.org/10.1038/s41587-019-0209-9

Buigues C, Fernández-Garrido J, Pruimboom L, Hoogland AJ, Navarro-Martínez R, Martínez-Martínez M, Verdejo Y, Carmen Mascarós M, Peris C and Cauli O (2016) Effect of a prebiotic formulation on frailty syndrome: A randomized, double-blind clinical trial. International Journal of Molecular Sciences 17(6), 932. https://doi.org/10.3390/ijms17060932

Callahan BJ, McMurdie PJ, Rosen MJ, Han AW, Johnson AJA and Holmes SP (2016) DADA2: High-resolution sample inference from Illumina amplicon data. Nature Methods 13(7), 581-583. https://doi.org/10.1038/nmeth.3869

Callahan BJ, Sankaran K, Fukuyama JA, Mcmurdie PJ and Holmes SP (2016) Open peer review workflow for microbiome data analysis: From raw reads to community analyses. F1000Research 5, 1492. https://doi.org/10.12688/f1000research.8986.1

Canani RB, Costanzo MD, Leone L, Pedata M, Meli R and Calignano A (2011) Potential beneficial effects of butyrate in intestinal and extraintestinal diseases. World Journal of Gastroenterology 17(12), 1519-1528. https://doi.org/10.3748/wjg. v17.i12.1519

Cani PD, Possemiers S, Van de Wiele T, Guiot Y, Everard A, Rottier O, Geurts L, Naslain D, Neyrinck A, Lambert DM, Muccioli GG and Delzenne NM (2009) Changes in gut microbiota control inflammation in obese mice through a mechanism involving GLP-2-driven improvement of gut permeability. Gut 58(8), 1091-1103. https://doi.org/10.1136/ gut.2008.165886

Chen Y-M, Wei L, Chiu Y-S, Hsu Y-J, Tsai T-Y, Wang M-F and Huang C-C (2016) Lactobacillus plantarum TWK10 supplementation improves exercise performance and increases muscle mass in mice. Nutrients 8(4), 205. https://doi.org/ $10.3390 /$ nu8040205

Claesson MJ, Jeffery IB, Conde S, Power SE, O’Connor EM, Cusack S, Harris HMB, Coakley M, Lakshminarayanan B, O'Sullivan O, Fitzgerald GF, Deane J, O'Connor M, Harnedy N, O'Connor K, O'Mahony D, van Sinderen D, Wallace M, Brennan L, Stanton C, Marchesi JR, Fitzgerald AP, Shanahan F, Hill C, Ross RP and O'Toole PW (2012) Gut microbiota composition correlates with diet and health in the elderly. Nature 488(7410), 178-184. https://doi.org/10.1038/nature11319

Collins CE, Burrows TL, Rollo ME, Boggess MM, Watson JF, Guest M, Duncanson K, Pezdirc Kand Hutchesson MJ (2015) The comparative validity and reproducibility of a diet quality index for adults: The Australian recommended food score. Nutrients 7(2), 785-798. https://doi.org/10.3390/nu7020785

Couto MR, Gonçalves P, Magro F and Martel F (2020) Microbiota-derived butyrate regulates intestinal inflammation: Focus on inflammatory bowel disease. Pharmacological Research 159, 104947. https://doi.org/10.1016/j.phrs.2020.104947

Cruz-Jentoft AJ, Bahat G, Bauer J, Boirie Y, Bruyère O, Cederholm T, Cooper C, Landi F, Rolland Y, Sayer AA, Schneider SM, Sieber CC, Topinkova E, Vandewoude M, Visser M, Zamboni M, Bautmans I, Baeyens J-P, Cesari M, Cherubini A, Kanis J, Maggio M, Martin F, Michel J-P, Pitkala K, Reginster J-Y, Rizzoli R, Sánchez-Rodríguez D and Schols J (2019) Sarcopenia: Revised European consensus on definition and diagnosis. Age and Ageing 48(1), 16-31. https://doi.org/10.1093/ ageing/afy169

Davis JA, Collier F, Mohebbi M, Stuart AL, Loughman A, Pasco JA and Jacka FN (2020) Obesity, Akkermansia muciniphila, and proton pump inhibitors: Is there a link? Obesity Research and Clinical Practice 14(6), 524-530. https://doi.org/10.1016/ j.orcp.2020.10.006

Davis JA, Mohebbi M, Collier F, Loughman A, Shivappa N, James RH, Pasco JA and Jacka FN (2021) Diet quality and a traditional dietary pattern predict lean mass in Australian women: Longitudinal data from the Geelong osteoporosis study. Preventive Medicine Reports 21, 101316. https://doi.org/10.1016/j.pmedr.2021.101316

den Besten G, Lange K, Havinga R, van Dijk TH, Gerding A, van Eunen K, Müller M, Groen AK, Hooiveld GJ, Bakker BM and Reijngoud DJ (2013) Gut-derived short-chain fatty acids are vividly assimilated into host carbohydrates and lipids. American Journal of Physiology - Gastrointestinal and Liver Physiology 305(12), G900-10. https://doi.org/10.1152/ ajpgi.00265.2013

Donovan SM (2017) Introduction to the special focus issue on the impact of diet on gut microbiota composition and function and future opportunities for nutritional modulation of the gut microbiome to improve human health. Gut Microbes 8(2), 75-81. https://doi.org/10.1080/19490976.2017.1299309

Duncan SH, Hold GL, Barcenilla A, Stewart CS and Flint HJ (2002) Roseburia intestinalis sp. nov., a novel saccharolytic, butyrate-producing bacterium from human faeces. International Journal of Systematic and Evolutionary Microbiology 52(5), 1615-1620. https://doi.org/10.1099/ijs.0.02143-0

Everard A, Lazarevic V, Derrien M, Girard M, Muccioli GM, Neyrinck AM, Possemiers S, Van Holle A, François P, De Vos WM, Delzenne NM, Schrenzel J and Cani PD (2011) Responses of gut microbiota and glucose and lipid metabolism to prebiotics in genetic obese and diet-induced leptin-resistant mice. Diabetes 60(11), 2775-2786. https://doi.org/10.2337/ db11-0227

Ferrara CM, Goldberg AP, Ortmeyer HK and Ryan AS (2006) Effects of aerobic and resistive exercise training on glucose disposal and skeletal muscle metabolism in older men. Journals of Gerontology - Series A Biological Sciences and Medical Sciences 61(5), 480-487. https://doi.org/10.1093/gerona/61.5.480 
Flint HJ (2012) The impact of nutrition on the human microbiome. Nutrition Reviews 70, S10-S13. https://doi.org/10.1111/ j.1753-4887.2012.00499.x

Ghosh TS, Rampelli S, Jeffery IB, Santoro A, Neto M, Capri M, Giampieri E, Jennings A, Candela M, Turroni S, Zoetendal EG, Hermes GDA, Elodie C, Meunier N, Brugere CM, Guillot EP, Berendsen AM, De Groot LCPGM, Feskins EJM, Kaluza J, Pietruszka B, Bielak MJ, Comte B, Maijo-Ferre M, Nicoletti C, De Vos WM, Fairweather-Tait S, Cassidy A, Brigidi P, Franceschi C and Toole PWO (2020) Mediterranean diet intervention alters the gut microbiome in older people reducing frailty and improving health status : The NU-AGE 1-year dietary intervention across five European countries. Gut 69, 1218-1228. https://doi.org/10.1136/gutjnl-2019-319654

Giles C and Ireland P (1996) Dietary Questionnaire for Epidemiological Studies (Version 2). Melbourne: Cancer Council Victoria.

Gloor GB, Macklaim JM, Pawlowsky-Glahn V and Egozcue JJ (2017) Microbiome datasets are compositional: And this is not optional. Frontiers in Microbiology 8, 2224. https://doi.org/10.3389/fmicb.2017.02224

Grosicki GJ, Fielding RA and Lustgarten MS (2018) Gut microbiota contribute to age-related changes in skeletal muscle size, composition, and function: Biological basis for a gut-muscle axis. Calcified Tissue International 102(4), 433-442. https:// doi.org/10.1007/s00223-017-0345-5

Harbison JE, Thomson RL, Wentworth JM, Louise J, Roth-Schulze A, Battersby RJ, Ngui KM, Penno MAS, Colman PG, Craig ME, Barry SC, Tran CD, Makrides M, Harrison LC and Couper JJ (2021) Associations between diet, the gut microbiome and short chain fatty acids in youth with islet autoimmunity and type 1 diabetes. Pediatric Diabetes 22(3), 425-433. https://doi.org/10.1111/pedi.13178

Holmstrøm K, Collins MD, Møller T, Falsen E and Lawson PA (2004) Subdoligranulum variabile gen. nov., sp. nov. from human feces. Anaerobe 10(3), 197-203. https://doi.org/10.1016/j.anaerobe.2004.01.004

Jackson MA, Jeffery IB, Beaumont M, Bell JT, Clark AG, Ley RE, O’Toole PW, Spector TD and Steves CJ (2016) Signatures of early frailty in the gut microbiota. Genome Medicine 8, 8. https://doi.org/10.1186/s13073-016-0262-7

Lahiri S, Kim H, Garcia-Perez I, Reza MM, Martin KA, Kundu P, Cox LM, Selkrig J, Posma JM, Zhang H, Padmanabhan P, Moret C, Gulyás B, Blaser MJ, Auwerx J, Holmes E, Nicholson J, Wahli W and Pettersson S (2019) The gut microbiota influences skeletal muscle mass and function in mice. Science Translational Medicine 11(502), eaan5662. https://doi.org/ 10.1126/scitranslmed.aan5662

Louis P, Duncan SH, McCrae SI, Millar J, Jackson MS and Flint HJ (2004) Restricted distribution of the butyrate kinase pathway among butyrate-producing bacteria from the human colon. Journal of Bacteriology 186(7), 2099-2106. https:// doi.org/10.1128/JB.186.7.2099-2106.2004

Maier L and Typas A (2017) Systematically investigating the impact of medication on the gut microbiome. Current Opinion in Microbiology 39, 128-135. https://doi.org/10.1016/j.mib.2017.11.001

McDonald D, Hyde E, Debelius JW, Morton JT, Gonzalez A, Ackermann G, Aksenov AA, Behsaz B, Brennan C, Chen Y, DeRight Goldasich L, Dorrestein PC, Dunn RR, Fahimipour AK, Gaffney J, Gilbert JA, Gogul G, Green JL, Hugenholtz P, Humphrey G, Huttenhower C, Jackson MA, Janssen S, Jeste DV, Jiang L, Kelley ST, Knights D, Kosciolek T, Ladau J, Leach J, Marotz C, Meleshko D, Melnik AV, Metcalf JL, Mohimani H, Montassier E, Navas-Molina J, Nguyen TT, Peddada S, Pevzner P, Pollard KS, Rahnavard G, Robbins-Pianka A, Sangwan N, Shorenstein J, Smarr L, Song SJ, Spector T, Swafford AD, Thackray VG, Thompson LR, Tripathi A, Vázquez-Baeza Y, Vrbanac A, Wischmeyer P, Wolfe E and Zhu Q (2018) American gut: An open platform for citizen science microbiome research. MSystems 3(3), e00031-18. https://doi.org/10.1128/msystems.00031-18

McGregor RA, Cameron-Smith D and Poppitt SD (2014) It is not just muscle mass: A review of muscle quality, composition and metabolism during ageing as determinants of muscle function and mobility in later life. Longevity \& Healthspan 3(1), 9. https://doi.org/10.1186/2046-2395-3-9

McMurdie PJ and Holmes S (2013) Phyloseq: An R package for reproducible interactive analysis and graphics of microbiome census data. PLoS One 8(4), e61217. https://doi.org/10.1371/journal.pone.0061217

Michaud M, Balardy L, Moulis G, Gaudin C, Peyrot C, Vellas B, Cesari M and Nourhashemi F (2013) Proinflammatory cytokines, aging, and age-related diseases. Journal of the American Medical Directors Association 14(12), 877-882. https:// doi.org/10.1016/J.JAMDA.2013.05.009

Mollica MP, Raso GM, Cavaliere G, Trinchese G, De Filippo C, Aceto S, Prisco M, Pirozzi C, Guida FD, Lama A, Crispino M, Tronino D, Vaio PD, Canani RB, Calignano A and Meli R (2017) Butyrate regulates liver mitochondrial function, efficiency, and dynamics in insulin-resistant obese mice. Diabetes 66(5), 1405-1418. https://doi.org/10.2337/db16-0924

Morley JE (1997) Anorexia of aging: Physiologic and pathologic. American Journal of Clinical Nutrition 66(4), 760-763. https:// doi.org/10.1093/ajcn/66.4.760

Morrison DJ and Preston T (2016) Formation of short chain fatty acids by the gut microbiota and their impact on human metabolism. Gut Microbes 7(3), 189-200. https://doi.org/10.1080/19490976.2015.1134082

Pacy PJ, Price GM, Halliday D, Quevedo MR and Millward DJ (1994) Nitrogen homoeostasis in man: The diurnal responses of protein synthesis and degradation and amino acid oxidation to diets with increasing protein intakes. Clinical Science 86(1), 103-118. https://doi.org/10.1042/cs0860103 
Pasco JA, Nicholson GC and Kotowicz MA (2012) Cohort profile: Geelong osteoporosis study. International Journal of Epidemiology 41(6), 1565-1575. https://doi.org/10.1093/ije/dyr148

Phillips CM, Chen L-W, Heude B, Bernard JY, Harvey NC, Duijts L, Mensink-Bout SM, Polanska K, Mancano G, Suderman M, Shivappa N and Hébert JR (2019) Dietary inflammatory index and non-communicable disease risk. A narrative review. Nutrients 11(8), 1873. https://doi.org/10.3390/nu11081873

Pryde SE, Duncan SH, Hold GL, Stewart CS and Flint HJ (2002) The microbiology of butyrate formation in the human colon. FEMS Microbiology Letters 217(2), 133-139. https://doi.org/10.1111/j.1574-6968.2002.tb11467.x

R Core Team (2013) R: A Language and Environment for Statistical Computing. R Foundation for Statistical Computing. 6 April, 2020 Available at http://www.r-project.org/.

Reichardt N, Duncan SH, Young P, Belenguer A, Leitch CM, Scott KP, Flint HJ and Louis P (2014) Phylogenetic distribution of three pathways for propionate production within the human gut microbiota. The ISME Journal 8, 1323-1335. https:// doi.org/10.1038/ismej.2014.14

Richardson S (1991) The timed "up \& go": A test of basic functional mobility for frail elderly persons. Journal of the American Geriatrics Society 39(2), 142-148. https://doi.org/10.1111/j.1532-5415.1991.tb01616.x

Ríos-Covián D, Ruas-Madiedo P, Margolles A, Gueimonde M, De los Reyes-Gavilán CG and Salazar N (2016) Intestinal short chain fatty acids and their link with diet and human health. Frontiers in Microbiology 7, 185. https://doi.org/10.3389/ fmicb.2016.00185

Rivière A, Selak M, Lantin D, Leroy F and De Vuyst L (2016) Bifidobacteria and butyrate-producing colon bacteria: Importance and strategies for their stimulation in the human gut. Frontiers in Microbiology 7, 979. https://doi.org/ 10.3389/fmicb.2016.00979

Roager HM, Hansen LBS, Bahl MI, Frandsen HL, Carvalho V, Gøbel RJ, Dalgaard MD, Plichta DR, Sparholt MH, Vestergaard H, Hansen T, Sicheritz-Pontén T, Nielsen HB, Pedersen O, Lauritzen L, Kristensen M, Gupta R and Licht TR (2016) Colonic transit time is related to bacterial metabolism and mucosal turnover in the gut. Nature Microbiology 1(9), 1-9. https://doi.org/10.1038/nmicrobiol.2016.93

Roberts HC, Denison HJ, Martin HJ, Patel HP, Syddall H, Cooper C and Sayer AA (2011) A review of the measurement of grip strength in clinical and epidemiological studies: Towards a standardised approach. Age and Ageing 40(4), 423-429. https://doi.org/10.1093/ageing/afr051

Robertson MD, Wright JW, Loizon E, Debard C, Vidal H, Shojaee-Moradie F, Russell-Jones D and Umpleby AM (2012) Insulin-sensitizing effects on muscle and adipose tissue after dietary fiber intake in men and women with metabolic syndrome. Journal of Clinical Endocrinology and Metabolism 97(9), 3326-3332. https://doi.org/10.1210/jc.2012-1513

Ruiz-Saavedra S, Salazar N, Suárez A, De los Reyes-Gavilán CG, Gueimonde M and González S (2020) Comparison of different dietary indices as predictors of inflammation, oxidative stress and intestinal microbiota in middle-aged and elderly subjects. Nutrients 12(12), 1-17. https://doi.org/10.3390/nu12123828

Salminen A, Kaarniranta K and Kauppinen A (2012) Inflammaging: Disturbed interplay between autophagy and inflammasomes. Aging 4(3), 166-175. https://doi.org/10.18632/aging.100444

Schwiertz A, Hold GL, Duncan SH, Gruhl B, Collins MD, Lawson PA, Flint HJ and Blaut M (2002) Anaerostipes caccae gen. nov., sp. nov., a new saccharolytic, acetate-utilising, butyrate-producing bacterium from human faeces. Systematic and Applied Microbiology 25(1), 46-51. https://doi.org/10.1078/0723-2020-00096

Shetty SA, Zuffa S, Bui TPN, Aalvink S, Smidt H and De Vos WM (2018) Reclassification of eubacterium hallii as Anaerobutyricum hallii gen. nov., comb. nov., and description of Anaerobutyricum soehngenii sp. nov., a butyrate and propionate-producing bacterium from infant faeces. International Journal of Systematic and Evolutionary Microbiology 68(12), 3741-3746. https://doi.org/10.1099/ijsem.0.003041

Shivappa N, Steck SE, Hurley TG, Hussey JR and Hébert JR (2013) Designing and developing a literature-derived, populationbased dietary inflammatory index. Public Health Nutrition 17(8), 1689-1696. https://doi.org/10.1017/S1368980013002115

Shook RP, Hand GA, O’Connor DP, Thomas DM, Hurley TG, Hébert JR, Drenowatz C, Welk GJ, Carriquiry AL and Blair SN (2018) Energy intake derived from an energy balance equation, validated activity monitors, and dual x-ray absorptiometry can provide acceptable caloric intake data among young adults. Journal of Nutrition 148(3), 490-496. https://doi.org/ 10.1093/jn/nxx029

Soto-Martin EC, Warnke I, Farquharson FM, Christodoulou M, Horgan G, Derrien M, Faurie JM, Flint HJ, Duncan SH and Louis P (2020) Vitamin biosynthesis by human gut butyrate-producing bacteria and cross-feeding in synthetic microbial communities. MBio 11(4), 1-18. https://doi.org/10.1128/mBio.00886-20

Sun QH, Liu ZJ, Zhang L, Wei H, Song LJ, Zhu SW, He MB and Duan LP (2021) Sex-based differences in fecal short-chain fatty acid and gut microbiota in irritable bowel syndrome patients. Journal of Digestive Diseases 22(5), 246-255. https:// doi.org/10.1111/1751-2980.12988

Tabung FK, Steck SE, Zhang J, Ma Y, Liese AD, Agalliu I, Hingle M, Hou L, Hurley TG, Jiao L, Martin LW, Millen AE, Park HL, Rosal MC, Shikany JM, Shivappa N, Ockene JK and Hebert JR (2015) Construct validation of the dietary inflammatory index among postmenopausal women. Annals of Epidemiology 25(6), 398-405. https://doi.org/10.1016/ j.annepidem.2015.03.009 
Tavakoli S, Dorosty-motlagh AR, Hoshiar-Rad A, Eshraghian MR, Sotoudeh G, Azadbakht L, Karimi M and JalaliFarahani S (2016) Is dietary diversity a proxy measurement of nutrient adequacy in Iranian elderly women? Appetite 105, 468-476. https://doi.org/10.1016/j.appet.2016.06.011

Ticinesi A, Lauretani F, Milani C, Nouvenne A, Tana C, Del Rio D, Maggio M, Ventura M and Meschi T (2017) Aging gut microbiota at the cross-road between nutrition, physical frailty, and sarcopenia: Is there a gut-muscle Axis? Nutrients 9(12), 1303. https://doi.org/10.3390/nu9121303

Walsh ME, Bhattacharya A, Sataranatarajan K, Qaisar R, Sloane L, Rahman MM, Kinter M and Remmen HV (2015) The histone deacetylase inhibitor butyrate improves metabolism and reduces muscle atrophy during aging. Aging Cell 14(6), 957-970. https://doi.org/10.1111/acel.12387

Whitman WB and John Wiley \& Sons (eds) (2015) Bergey's Manual of Systematic of Archaea and Bacteria, 1st Edn. New York: Springer. https://doi.org/10.1002/9781118960608

Wu GD, Chen J, Hoffmann C, Bittinger K, Chen Y-Y, Keilbaugh SA, Bewtra M, Knights D, Walters WA, Knight R, Sinha R, Gilroy E, Gupta K, Baldassano R, Nessel L, Li H, Bushman FD and Lewis JD (2011) Linking long-term dietary patterns with gut microbial enterotypes. Science 334(6052), 105-108. https://doi.org/10.1126/science.1208344

Zhang L, Liao J, Chen Q, Chen M, Kuang Y, Chen L and He W (2020) Characterization of the gut microbiota in frail elderly patients. Aging Clinical and Experimental Research 32(10), 2001-2011. https://doi.org/10.1007/s40520-019-01385-2

Zheng J, Hoffman KL, Chen JS, Shivappa N, Sood A, Browman GJ, Dirba DD, Hanash S, Wei P, Hebert JR, Petrosino JF, Schembre SM and Daniel CR (2020) Dietary inflammatory potential in relation to the gut microbiome: Results from a crosssectional study. British Journal of Nutrition 124(9), 931-942. https://doi.org/10.1017/S0007114520001853

Cite this article: Davis J.A., Collier F., Mohebbi M., Pasco J.A., Shivappa N., Hébert J.R., Jacka F.N., and Loughman A. 2021. The associations of butyrate-producing bacteria of the gut microbiome with diet quality and muscle health. Gut Microbiome, 2, e2, 1-18. https://doi.org/10.1017/gmb.2021.2

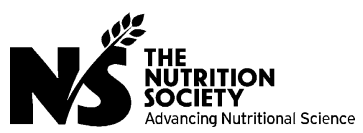

